\title{
EFFECTIVENESS OF EMPLOYEE RESILIENCE AMONG INFORMATION TECHNOLOGY SECTOR EMPLOYEES: AN EMPIRICAL STUDY
}

\author{
Mr. P Sai Kumar ${ }^{1}$ Dr. V. Tulasi Das ${ }^{2}$ \\ ${ }^{1}$ Research Scholar, Dept. of HRM, Acharya Nagarjuna University, Guntur, A.P. \\ ${ }^{2}$ Assoc. Professor, Chairman BoS (PG) in HRM, Dept. of Human Resource \\ Management, Acharya Nagarjuna University, Guntur, AP., (Correspondent Author)
}

Article DOI: https://doi.org/10.36713/epra9643

DOI No: 10.36713/epra9643

\begin{abstract}
COVID-19 had a global impact on most organizations' operations and workforce, particularly with regard to safety, mobility, productivity, engagement, and security. The biggest challenge of IT companies face today is managing virtual work, while balancing employee safety with company security. They must sustain secured operations and adopt new collaborative strategies to maintain workforce productivity. Looking ahead, companies must make business resiliency a continuous process. This pandemic represents an opportunity for Companies to make rapid, well-informed decisions and expedite arrangements to safeguard their workforce, mitigate business disruption, and ensure that critical operations continue. An informed decision could build trust, resiliency, and a culture of innovation; a poor decision could pose a real reputational risk. To enable a more resilient business, IT organizations should focus on individual resilience and this individual resilience ensure resiliency of organisation. Therefore, the current research paper examines the effectiveness of resilience among IT sector employees and present the results.
\end{abstract}

KEYWORDS: Employee Resilience, Productivity, Virtual Workforce, Sustainability, Strategy.

\section{INTRODUCTION}

Human resource management (HRM) has made considerable strides in recent decades, exploring with a plethora of new concepts as a consequence of dynamic environmental changes throughout the globe (Netty Merdiaty et al., 2021). The due to the rapid economic upheaval mandates that every organization own a strong understanding about how to maintain its employees and organizations successful.

Resilience and well-being are two key concepts in Human Resource Management (HRM) that can enable individuals and organizations to perform better. In today's challenging and diversified work environment, resilience is becoming highly relevant and plays an essential role in competing in the market and undergoing psychological change. Resilience is a concept analogous to engagement and leadership something which we encourage in the workplace. Resilient behaviour in the context of its parent school of thought and its relevance to organisational studies (Khaliq Ur Rehman et al., 2021). However, just for clarification and operationalization, the term "resilient behaviour" is defined as "the ability to maintain positive adjustment in the face of adversity." A person's capability or capacities to revert/overcome a terrible situation is referred to as resilient conduct. The ability of an organization to overcome a crisis is referred to as organizational resilient behaviour. In times of change, resilient behaviour is also required in organizations.

The concept of resilience can be constructed on strong theoretical foundations, and a cohesive set of resilience-enhancing HR practices has the potential to improve employees' psychological capital, attitudes, and behaviour, as well as organizational performance, not just in turbulent times but also in key moments of relative calm. Positive psychology concepts like resilience, subjective health, hope, and optimism can help HRM manage employee performance and organizational issues by aiding HR initiatives (Paul, H., \& Garg, P., 2019). 


\section{FACTORS INFLUENCING EMPLOYEE RESILIENCE}

Employee resilience is viewed as a dynamic, reflective process that includes resolving personal conflicts, achieving work-life balance and reacting to the organizational demands. The interrelationship of resilience and support for work-life balance is referred to as the "dynamic and reflective process." A sense of accomplishment, family support and financial freedom were found to be the most important elements in enabling resilience.

Resilience factors (positive thinking, adaptability, taking responsibility and separating work and life) help employees to stay in the workforce by allowing them to balance work and family life. In this context, resilience is discovered to be a societal process of accessing resources and acting to overcome adversity, rather than a collection of personal attributes. First-line managers who are resilient are more likely to shift their focus from negative to positive experiences, from a principle-based approach to flexibility, from task-cantered to personcantered thinking, and from the organization to the family.

\section{IMPACT OF DEVELOPING EMPLOYEE RESILIENCE}

Employee resilience can help to reduce job uncertainty, stress, and interpersonal but ineffective work behaviours (Shoss et al., 2018). When it comes to adapting to difficult conditions, resilience is crucial (Malik, P \& Garg, P, 2017). It helps to improve employees' behaviour in dynamic and highstress environments.

HR strategies will not only help to improve individual performance by promoting employee resilience and enhancing job outcomes, but they will also help to build and sustain organizational value. It helps to cope with emotional distress and motivate employees to make effective decisions and take appropriate action to overcome critical challenges. When employees have the support of their family and friends, they develop resilience, which ultimately leads to increased employee engagement (HetzelRiggin et al., 2019). Resilience is the ability to cope with stress in a constructive manner, and it provides tremendous health benefits. It's linked to longer life, lower rates of stress, and higher life satisfaction (Malloy, 2017). "There's a sense of control, and it makes one feel better in general."

Wellbeing, psychological stress, proactive personality, commitment to change, creative behaviour, task/OCB performance, work engagement, commitment to the organization, burnout, emotional fatigue, and job satisfaction all seem to be outcomes attributed with employee resilience (Eric Barends et al., 2021). Additionally, the study showed that self-protective resources like self-efficacy, positive affect, and a work-related sense of coherence, as well as social resources including co-worker social support and a high-quality leader-member interchange, are important predictors of employee resilience. Identified the need for building a resilient workplace culture to enhance employee performance in managing with workplace stressors and reduce adverse health, cost, and productivity outcomes of poor mental health (AHA CEO, 2016).

\section{BUILDING EMPLOYEE RESILIENCE IN ORGANIZATIONS}

Employees that are emotionally resilient know how to care for them, feel comfortable expressing themselves, and do not judge themselves. Employees that are resilient believe they have influence over their destiny. Employee resilience is reflected in adaptive, learning, and networking behaviours in the workplace (Kuntz, 2016). A resilient employee leverages work resources in ways that benefit the organization and also contribute to personal wellbeing and growth. Also indicates that organizations develop employee resilience through a number of social processes, facilitated by leaders.

\section{REVIEW OF LITERATURE}

Rahul Goyal, (2021) According to the Global Workplace Study 2020 by the ADP Research Institute, the average is just $15 \%$, which puts India on the top when it comes to workplace resilience. $20 \%$ feel they are fully engaged, whereas the global average is only $14 \%$, and $32 \%$ of workers in India feel highly resilient to their work environment. Indian employees are found to be amongst the most resilient employees in the world.

Barends, $\mathbf{E}$ et. al., (2021) According to findings in management and organizations, resilience is likely to enable employees to retain and recoup resources at work, as well as mitigate resource loss that can lead to psychological discomfort, emotional fatigue, and burnout. Psychological stress, proactive work attitude, creative behaviour, commitment to change, performance (task/OCB), employee engagement, organizational commitment, emotional exhaustion, and job satisfaction are among the workrelated attitudes and outcomes that have been identified in a review of papers. Furthermore, the analysis revealed that self-protective resources including self-efficacy, optimistic affect, and a workrelated sense of coherence, along with social resources such as co-worker social support and highquality leader-member interaction, are effective predictors of employee resilience. Finally, interventions aimed at improving employee resilience are effective, but their efficacy is influenced by multiple other design and delivery factors. 
Kanwal, Maqsood and Karim, (2020) the research explored the relationship between "meaningful work" and "employee identity," with the variable "employee resilience" acting as a mediator among the employees of call Centre's in Lahore, Pakistan. Cross-sectional analysis was used to evaluate a significant subset of constructs. The findings revealed that meaningful work has a significant impact on employee resilience, allowing employees to overcome adversity while maintaining their identity. Furthermore, it was determined that if an organization focuses on providing meaningful work, employees become more resilient and their initiatives result in positive outcomes.

Natnaporn et. al., (2020) Employee resilience and the social climate have also been considered as mediators in the study. Employee resilience and the role of the social climate as a moderator Furthermore, it is imperative to examine how well-being and selfresilience affect organizational resilience, which will improve the company's performance.

Meysam, Arbuzia (2019) the focus of this research will be how resilience training affects nurses' QWL and job stress. Except for social integration, overall working environment, and organizational constitutionalism, there was no statistically significant difference between the intervention and control groups in terms of QWL throughout the intervention. The findings demonstrate that resilience training may be optimized to enhance the organization's QWL measures of social integration, complete life space, and constitutionalism.

Nadeem et.al, (2019) According to the study, employee service performance, organizational citizenship behaviour (OCB), and employee resilience are all related to higher work systems (HPWS) among Pakistani service sector employees. Employee resilience plays a crucial part in achieving employee service-related behaviours and OCB strategies, and HPWS creates an environment in which employees feel resilient. Furthermore, employee resilience was partially mediated by both the indirect associations that exist between HPWS and employee outcomes.

Naswall, $\mathbf{K}$ et.al, (2019) Scales that measure resilience in the general public, such as the 10-item Connor-Davidson Resilience Scale (CD-RISC 10) or the 14-item Resilience Scale (RS-14), as well as scales that focus exclusively on employee resilience, such as the nine-item Employee Resilience Scale, were used in studies included in this review.

\section{RESEARCH GAP}

There are number of researches focussed on developing scale for the resilience in various sector but usability of these scales is not validated in IT sector, particularly in Indian context. Therefore, this empirical study is conducted to examine the usability of resilience questionnaires in IT sector in Indian context.

\section{OBJECTIVES OF THE STUDY}

- To study literature and find the factors influencing resilience in information technology sector.

- To examine the effectiveness of resilience in select information technology organisation in Hitech City, Hyderabad.

- To put forth some suggestions based on the findings.

\section{SAMPLE AND DATA COLLECTION}

A quantitative approach was followed in this exploratory study. The 18-item scale is adopted from the article "Employee Resilience in Organisation: Development of a New Scale" by Muhammad Taufiq Amir and Peter Standen (2012). The participants selected for this study consisted of select information technology organisation in Hitech city, Hyderabad employees. 1150 questionnaires were distributed among the select companies. Convenience sampling technique was deployed in sample selection. The respondents were solicited to complete the resilience questionnaire. The resultant response rate of useable questionnaires was $99.5 \%$ (1145).

\section{DATA ANALYSIS \\ Model fit of Innovation Model}

Values of different fit indices; GFI, IFI, CFI, NFI greater than 0.9 considered as good fit and RMSEA values 0.05 or less indicates close to fit, between 0.05 to 0.08 indicates reasonable fit and values between 0.08 to 0.10 show marginal fit (Kline, 2001).

Structural Equation Modelling (SEM) is conducted with all ten variables and data shows that in select $\mathrm{IT}$ companies $\mathrm{df}=4.822$, GFI $=.903$, NFI= $.918, \mathrm{IFI}=.915, \mathrm{TLI}=.907, \mathrm{CFI}=.914, \mathrm{RMSEA}=$ .075 the model is improvised after allowing modification indices. 


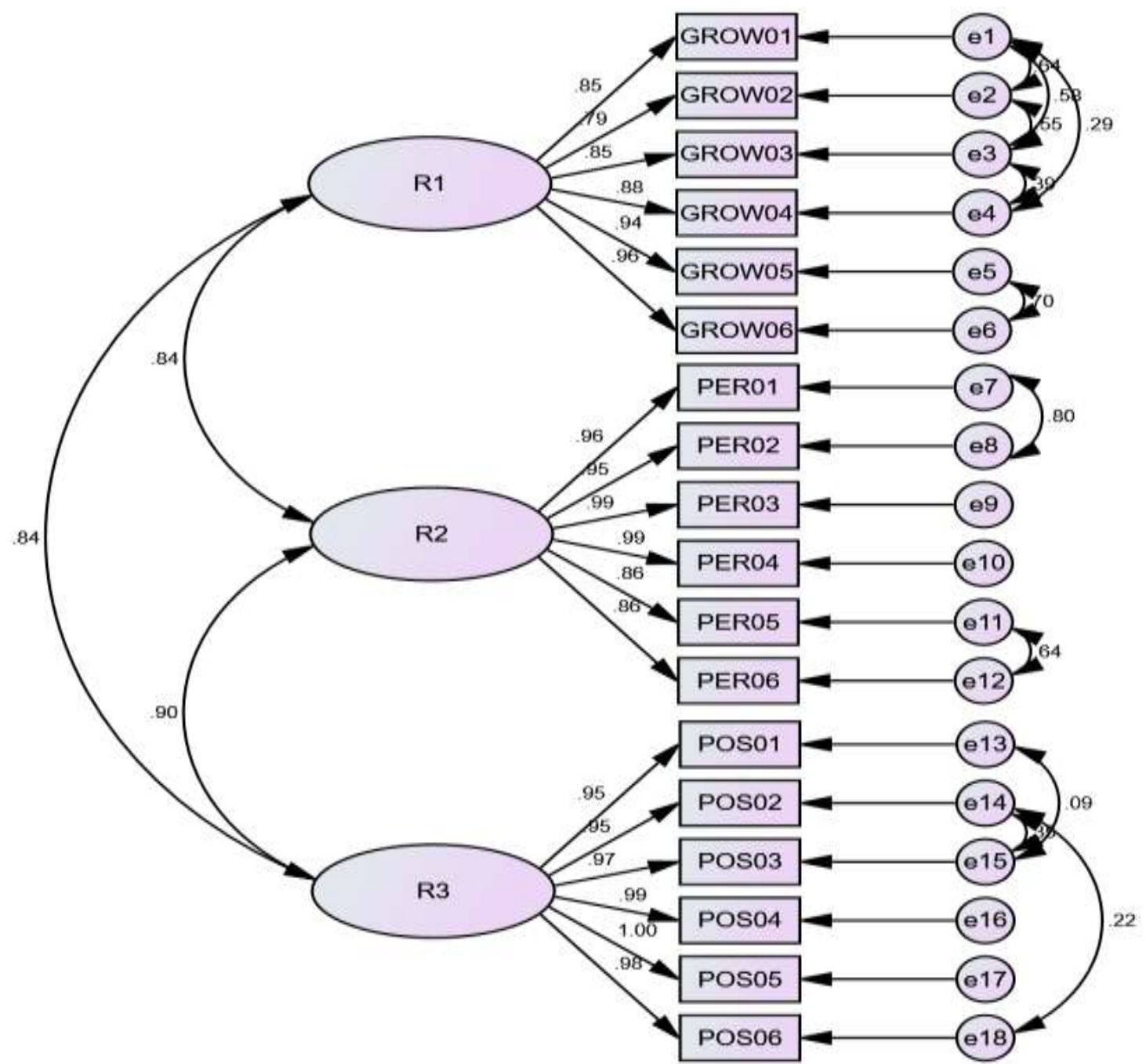

Figure-1: Resilience Model

Divergent Validity\& Convergent Validity of Resilience Model

Table-1: Divergent Validity\& Convergent Validity of Resilience Model in Select IT Companies

\begin{tabular}{|l|c|c|l|c|c|}
\hline & CR & AVE & Growth & Perseverance & $\begin{array}{l}\text { Positive } \\
\text { Emotion }\end{array}$ \\
\hline Growth & 0.95489 & 0.7799 & $\mathbf{0 . 8 8 3}$ & & \\
\hline Perseverance & 0.97764 & 0.87971 & 0.838 & $\mathbf{0 . 9 3 8}$ & \\
\hline $\begin{array}{l}\text { Positive } \\
\text { Emotion }\end{array}$ & 0.991 & 0.94836 & 0.836 & 0.9 & $\mathbf{0 . 9 7 4}$ \\
\hline
\end{tabular}

(Source: Primary Data)

Convergent validity was assessed through $\mathrm{CR}$ and AVE. The required levels of CR and AVE should be equal or more than 0.6 and 0.5 respectively (Hair et al., 2010). CR and AVE were also used to establish the reliability of the measurement model. CR is an alternative measure to Cronbach's Alpha, it is recommended by Chin (1998) as an ideal measure to overcome some deficiencies in Cronbach's alpha. The CR should be 0.60 or higher, while the minimum threshold for an AVE should be 0.5 or higher to indicate adequate reliability (Awang, 2015). The composite reliability (CR) and average variance 
explained (AVE) values for the final measurement model of Resilience are presented in above table. From the above table it is observed that all $\mathrm{CR}$ values are more than 0.7 and AVE values are more than 0.5, hence supporting their convergent validity (Hair et al., 2010).

The recommended approach for establishing divergent Validity is to compare the squared correlation between two constructs with either of their individual AVE estimates (Hair et al., 1998). The AVE estimates should be greater than the squared correlation estimate. In addition to distinctiveness of constructs, divergent Validity also means that individual measured items should represent only one latent construct. Form the above table it is observed that the AVE estimates are greater than the squared correlation estimates, hence supporting divergent validity (Hair et al., 1998).

\section{Employee's Perception on Resilience}

Table- 2: Descriptive Statistics of Employee Perceptions on Commitment to Growth

\begin{tabular}{|c|c|c|c|}
\hline \multicolumn{4}{|c|}{ Descriptive Statistics } \\
\hline & $\mathrm{N}$ & Mean & Std. Deviation \\
\hline $\begin{array}{l}\text { You see difficult as challenges and } \\
\text { opportunities to learn }\end{array}$ & 1145 & 3.53 & 1.541 \\
\hline $\begin{array}{l}\text { You think about your mistakes and learn } \\
\text { from them }\end{array}$ & 1145 & 3.47 & 1.573 \\
\hline $\begin{array}{l}\text { You think how you could have prevented } \\
\text { unforeseen problems when they occur }\end{array}$ & 1145 & 3.53 & 1.547 \\
\hline $\begin{array}{l}\text { You can grow in positive ways by } \\
\text { dealing with difficult situation }\end{array}$ & 1145 & 3.61 & 1.532 \\
\hline $\begin{array}{l}\text { You actively look for ways to overcome } \\
\text { the challenges you encounter }\end{array}$ & 1145 & 3.71 & 1.473 \\
\hline $\begin{array}{l}\text { You often seek feedback on your work } \\
\text { from others }\end{array}$ & 1145 & 3.72 & 1.457 \\
\hline Valid N (listwise) & 1145 & & \\
\hline
\end{tabular}

(Source: Primary Data)

From the above table it is understood that in Commitment to Growth "You often seek feedback on your work from others" registered highest mean value and lowest standard deviation (1.457). "You think about your mistakes and learn from them" registered lowest mean value.

Table- 3: Descriptive Statistics of Employee Perceptions on Perseverance

\begin{tabular}{|l|r|r|r|}
\hline \multicolumn{4}{|c|}{ Descriptive Statistics } \\
\hline $\begin{array}{l}\text { You are able to adapt to } \\
\text { change }\end{array}$ & 1145 & 3.75 & N \\
\hline $\begin{array}{l}\text { You look for creative ways to } \\
\text { alter difficult situation }\end{array}$ & 1145 & 3.74 & 1.424 \\
\hline $\begin{array}{l}\text { You tend to bounce back after } \\
\text { illness or hardship }\end{array}$ & 1145 & 3.72 & 1.408 \\
\hline $\begin{array}{l}\text { You don't give up when things } \\
\text { look helpless }\end{array}$ & 1145 & 3.72 & 1.406 \\
\hline $\begin{array}{l}\text { You tend to recover quickly } \\
\text { from stressful events }\end{array}$ & 1145 & 3.74 & 1.457 \\
\hline $\begin{array}{l}\text { You are not easily discouraged } \\
\text { by failure }\end{array}$ & 1145 & 3.74 & 1.452 \\
\hline Valid N (listwise) & 1145 & & \\
\hline
\end{tabular}

(Source: Primary Data)

From the above table it is understood that in Perseverance "You are able to adapt to change" registered highest mean value (3.75) and lowest standard deviation (1.405). "You tend to bounce back after illness or hardship" and "You don't give up when things look helpless" registered lowest mean value. 
Table- 4: Descriptive Statistics of Employee Perceptions on Positive Emotion

\begin{tabular}{|l|r|r|r|}
\hline \multicolumn{4}{|c|}{ Descriptive Statistics } \\
\hline $\begin{array}{l}\text { You can get through difficult } \\
\text { times at work because You've } \\
\text { experienced difficulty before }\end{array}$ & 1145 & 3.74 & 1.460 \\
\hline $\begin{array}{l}\text { You are interested in facing } \\
\text { and solving problems }\end{array}$ & 1145 & 3.74 & 1.452 \\
\hline $\begin{array}{l}\text { You are usually confident in } \\
\text { doing whatever I choose }\end{array}$ & 1145 & 3.76 & 1.435 \\
\hline $\begin{array}{l}\text { You are usually optimistic and } \\
\text { hopeful }\end{array}$ & 1145 & 3.80 & 1.439 \\
\hline $\begin{array}{l}\text { You are enthusiastic in facing } \\
\text { problems rather than avoiding } \\
\text { them }\end{array}$ & 1145 & 3.81 & 1.421 \\
\hline $\begin{array}{l}\text { You can see the humorous } \\
\text { side of a problem }\end{array}$ & 1145 & 3.80 & 1.438 \\
\hline Valid N (listwise) & 1145 & & \\
\hline
\end{tabular}

(Source: Primary Data)

From the above table it is understood that in Positive Emotion "You are enthusiastic in facing problems rather than avoiding them" registered highest mean value (3.81) and lowest standard deviation (1.421). "You can get through difficult times at work because You've experienced difficulty before" and "You are interested in facing and solving problems" registered lowest mean value.

\section{FINDINGS}

$>$ From the analysis it is found that all the 18 items and three variables in the model are fit for the resilience in the study area.

$>$ From the table-2 it is observed that in commitment to Growth factor of resilience "You often seek feedback on your work from others" registered highest mean value and "You think about your mistakes and learn from them" registered lowest mean value.

$>$ Table-3 emphasises that in Perseverance factor of resilience "You are able to adapt to change" registered highest mean value (3.75) and "You tend to bounce back after illness or hardship" and "You don't give up when things look helpless" registered lowest mean value.

$>$ From table- 4 it is understood that in Positive emotion factor of resilience "You are enthusiastic in facing problems rather than avoiding them" registered highest mean value (3.81) and lowest standard deviation (1.421). "You can get through difficult times at work because You've experienced difficulty before" and "You are interested in facing and solving problems" registered lowest mean value.

\section{SUGGESTIONS}

$\checkmark \quad$ The person who is expecting to grow should get healthy feedback from others, because how efficiently one may conduct self-study and self-motivation often no able to see beyond certain limit. Therefore, one who wish to grow should have a person in their life who can give healthy feedback. Here healthy feedback is not about only positive feedback or negative one but both according to the situation but in constructive path.

$\checkmark$ Covid-19 has caused illness to an individual or their families and many of them are not able to come out of that trauma. This trauma has huge impact on employee productivity and engagement. Therefore, organisations should conduct awareness camps with company doctors and provide guidance during illness. Post illness also requires some motivational support from the organisation and they should organise or share speeches of professional motivators.

$\checkmark \quad$ From the analysis it is found that employees are not interested to invite problems but they don't want avoid problems when they occur. So, the employees are well aware that avoiding is not solution for the problem and they try not to accept the job where there is a problem, but to sustain in any industry the employee should always be face all the potential problems. To overcome this escapism from problem the partial solution is to have teach company standard operating process during each potential situations and the guidelines for unexpected situations. The company should also motivate employees who want to handle problems by monetary benefits and more weightage during promotions. 


\section{CONCLUSION}

The research is conducted to examine the applicability of resilience scale in the IT sector in Indian context and the effectiveness of resilience among IT sector employees. For the research Muhammad Taufiq Amir and Peter Standen (2012) 18 item scale considered for the study. From the model fit test, it is found that all 18 items are found to be fit in resilience model for IT sector in Indian context. For commitment to growth; You often seek feedback on your work from others, for perseverance; You are able to adapt to change, for positive emotion; You are enthusiastic in facing problems rather than avoiding them registered highest mean value. Therefore, from the research it is concluded that according to IT sector employees they have more resilience qualities and they felt resilience is very important in current dynamic environment.

\section{Scope for Further Research}

The present research considered employees of IT companies in Hyderabad, in future researchers may involve employees of different geographical area to get valid results. In future researcher also can examine the resilience impact on outcome factors of companies like employee engagement and job performance.

\section{REFERENCES}

1. Netty Merdiaty, Khatijah Omar, Jumadil Saputra, Abdul Talib Bon. (2021). A Review of Resilience and Well-being in Human Resource Management Perspective Literature. 11th Annual International Conference on Industrial Engineering and Operations Management (pp. 4135-4149). Singapore: IEOM Society International.

2. Khaliq Ur Rehman,Mário Nuno Mata,José Moleiro Martins,Sabita Mariam. (2021). SHRM Practices Employee and Organizational Resilient. Journal of Open Innovation:Technology. Market and Complexity, 7 (2), 1-14.

3. Paul, H., \& Garg, P. (2019). Healing HRM through Positive Psychology: An Outlook. Procedia - Social and Behavioural Sciences. https://doi.org/10.1016/j.sbspro.2014.04.178.

4. Muhammad Taufiq Amir and Peter Standen (2012). Employee Resilience in Organizations: Development of a New Scale. Anzam, Pp: 1 - 17

5. Malik, $P \&$ \& Garg, P. (2017). Learning organization and work engagement: The mediating role of employee resilience. The International Journal of Human Resource Management, 1-24.

6. Hetzel-Riggin, M.D.; Swords,B.A.; Tuang,H.L.; Deck,J.M.; $\quad$ Spurgeon,N.S. (2019). Work Engagement and Resiliency Impact the Relationship Between Nursing Stress and Burnout. Psychol. Rep.

7. Eric Barends, Emilia Wietrak, Iulia Cioca and Denise Rousseau. (2021). Employee resilience: an evidence review. CIPD(Chartered Institute of
Personnel and Development. 1039). London: Center for Evidence-Based Management (CEBMa).

8. AHA CEO. (2016). RESILIENCE IN THE WORKPLACE. AHA Center for Workplace Health Research \& Evaluation

9. Kuntz, J. R. (2016). Developing Employee Resilience Through Organizational Initiatives. Society of Consulting Psychology .

10. Rahul Goyal. (2021). Global Workplace Study 2020. ADP Research Institute. HRK News Bureau.

11. Kanwal, Maqsood and Karim. (2020). The Impact of Meaningful Work on Employee Identity and the Mediating Role of Employee Resilience. Journal of Applied Research and Multidisciplinary Studies , 1 (1), 31-47.

12. Natnaporn Aeknarajindawat,Nattachai Aeknarajindawa,Damkerng Aswasuntrangkul. (2020). Role of Wellbeing Oriented HRM Practices towards the Employee Performance: Mediating Role of Employee Resilience and Social Climate. Sys Rev Pharm 2020: A multifaceted review journal in the field of pharmacy, 11 (3), 115-124.

13. Meysam Arbuzia, M. R. (2019). The Effect of Resilience Training on Quality of Work Life (QoWL) and Job Stress of Nurses in Emergency Department of Shahid Mohammadi Hospital in Bandar Abbas in 2018. J. Evolution Med. Dent. Sci , 8 (42), 3161-3164.

14. Naswall, K., Kuntz, J., Hodliffe, M., Malinen, S. (2019). Employee Resilience: Development and Validation of a Measure. Journal of Managerial Psychology , 34 (5), 353-367.

15. Awang, Z. (2015). SEM made simple: A gentle approach to learning structural equation modelling. Bandar BaruBangi, MPWS Rich Resources.

16. Chin W.W. (1998). Issues and opinion on structural equation modelling. MIS Quarterly, 22 (1), 7-16.

17. Fornell, C., \& Larker, D. F. (1981). Evaluating structural equation models with unobservable variables and measurement error. Journal of Marketing Research, 18, 39-50.

18. Hair, J. F., Anderson, R. E., Tatham, R. L. and Black, W. C. (1998). Multivariate data analysis. (5th ed.). Prentice-Hall, New Jersey.

19. Hair, J. F., Black, W. C., Babin, B. J., \& Anderson, R. E. (2010). Multivariate data analysis (7th ed.). Upper saddle River, New Jersey: Pearson Education International. 